\section{OS ESTUDOS CLÁSSICOS E A SOCIEDADE BRASILEIRA DE ESTUDOS CLÁSSICOS, ALGUNS COMENTÁRIOS HISTÓRICOS}

\author{
Pedro Paulo A. Funari* \\ Recebido em: 30/04/2019 \\ Aprovado em: 20/05/2019
}

\begin{abstract}
RESUMO: O artigo discute o contexto histórico da fundação da Sociedade Brasileira de Estudos Clássicos (1985) e da revista Classica (1989), iniciando pela explicitação da perspectiva, uma história social e cultural da ciência. Volta-se para a trajetória do ensino superior no Brasil, em seguida foca nos antecedentes imediatos. A resistência democrática relaciona-se com a academia, em geral, e com os Estudos Clássicos, no Brasil. Conclui-se com breve balanço e perspectivas.
\end{abstract}

PALAVRAS-CHAVE: estudos clássicos; ensino superior no Brasil; democracia.

\section{CLASSICS AND THE BRAZILIAN SOCIETY OF CLASSICAL STUDIES, SOME HISTORICAL COMMENTS}

\begin{abstract}
The paper discusses the historical context of the founding of Brazilian Society of Classical Studies (1985) and the journal Classica (1989), starting by stating the standpoint, a social and cultural history of the discipline. It turns to higher education in Brazil, then to Brazilian history to focus on the immediate antecedents. Democratic resistance relates to scholarship in general and to classics in Brazil. It ends with a brief assessment and outlook.
\end{abstract}

KEYWORDS: Classics; higher education in Brazil; democracy.

\footnotetext{
criação da Sociedade Brasileira de Estudos Clássicos, em 1985, e a da revista Classica, em 1989, marcam todo o desenvolvimento posterior da área e resultam, por sua
}

*Professor Titular, Departamento de História, Universidade Estadual de Campinas. Bolsista de produtividade em pesquisa do CNPq. ppfunari@uol.com.br

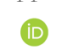


naquela ocasião, como estudante, antes de 1986, tendo, depois, continuado como professor universitário. Essas mais de três décadas merecem reflexões, como suscitado pela SBEC e por Classica. Neste artigo, começo com a explicitação da abordagem adotada: uma história social e cultural da ciência, neste caso, dos Estudos Clássicos. Segue-se um aceno à trajetória do país e do mundo à época, suas transformações. Centra-se, em seguida, no movimento que resultou na criação da SBEC e de Classica e das mudanças ensejadas por isso. Por fim, menciona-se de forma breve os rumos seguidos e as perspectivas.

\section{HistóRia Social E CUltural da ciênCia}

Nada se pode refletir, pensar ou expressar sem uma perspectiva. A tentativa de subtrair o sujeito de conhecimento do ato de perscrutar está fadada ao insucesso. A própria reflexão é o resultado do contato de um ator e pensador consigo mesmo e com outrem. Parece conveniente, assim, explicitar a abordagem adotada, como se apresentará, nas páginas seguintes, o tema. Há dois aspectos importantes a serem considerados: o acúmulo de ideias, por um lado, e a relação entre o contexto social e cultural e a ciência, por outro. Essa separação é arbitrária e heurística, até mesmo didática, mas continua a ser útil para diferenciar tanto o papel da dependência, sempre, do que precede e, ao mesmo tempo, incluir a historicidade radical do conhecimento (Latour, 1991). Todo saber depende do prévio, por definição. Mas cada época e circunstâncias produzem interpretações diversas, nem sempre tributárias, até mesmo contrárias ao que se propunha antes (Patterson, 2001). Poderia tratar-se de revoluções epistemológicas (Kuhn, 1996), ou, de maneira mais prosaica, da prevalência de outras ideias. Em tempos, no Brasil de 2019, de difusão do criacionismo, entende-se bem a ausência de um sentido, de uma evolução, de um télos absoluto, empírico e racional, mas da prevalência da sociedade e da cultura nas compreensões. Se isto se aplica às ciências em geral, tanto mais nas Humanidades e Ciências Sociais, na medida em que lidam com o humano.

\section{Os ESTUdOS SUPERIORES NO BRASIL}

O Brasil tardou a abrigar estudos superiores ou universitários (Bortolanza, 2017). Durante o período colonial, a Universidade de Coimbra, na Metrópole, Portugal, centralizava a formação de poucos e bons, pauci sed boni, aqueles que tinham a possibilidade. Esses usufruíam de uma educação clássica, fundada no domínio do latim e da tradição do que, depois, seria parte dos estudos clássicos, acrescidos da frequentação da tradição cristã latina. Isso está evidente em Gregório de Matos (1636-1696), mas a presença brasileira em Coimbra, ainda que diáfana, foi constante (Cunha, 2007).

Com a independência (1822), foram criados os cursos jurídicos, em 1827, em Olinda e São Paulo, duas cidades periféricas, na trilha de Coimbra, Oxford e Cambridge. A despeito da criação de alguns cursos superiores, como Engenharia e Medicina, foi apenas em 1934, com a Universidade de São Paulo, que surgia uma universidade ao modelo universalista das outras modernas, mundo afora. A partir daí, e por emulação, difundiram-se as instituições 
superiores integradas. A pós-graduação, como resultado, tardou a desenvolver-se. De início, seguia-se o modelo francês, latino e fluido, de doutoramentos sem regulamentação geral. O regime militar, filo-americano, introduziu reforma universitária nos moldes americanos, com a introdução dos créditos e períodos (terms), e da pós-graduação com mestrado e doutoramento, implementada na década de 1970, com a supervisão federal da Capes (Germano, 1994). Esse sistema contou, ainda, com o apoio do CNPq e, em alguns estados, com fundações de apoio à pesquisa, como Fapesp e Fapemig. Como resultado, em poucas décadas, o Brasil passou de uma posição marginal para a liderança acadêmica na América Latina.

\section{BRASIL, UMA HISTÓRIA ÚNICA}

Todas as nações, invenção moderna, apresentam trajetórias única e particulares. Isso dá-se por definição: cada uma é uma. No entanto, as nações hispano-americanas, antigas colônias espanholas, apresentam trajetórias compartilhadas, para além do idioma, à diferença da América portuguesa. Todas ibéricas compartilharam o patrimonialismo, as diferenças de status, a escravidão e o rebaixamento do trabalho manual, mas também a miscigenação, o que o cubano Fernando Ortiz (1983) chamaria de transculturação, o catolicismo em sua imensa variedade, entre outras características (Canclini, 1995). Entre as particularidades, muitas do que viria a ser o Brasil, estiveram certas feições medievais, do traçado das ruas à ordem monárquica, tudo com certa nonchalance, termo das elites para se referir a certa falta de vontade, desleixo, seja dos subalternos, seja delas mesmas, elites.

Entre os aspectos compartilhados, o poder do chefe ou caudilho, nomeado de diversas formas, como coronel, o compadrio, o arreglo. A monarquia (1822-1889), contudo, viria a dotar a sociedade brasileira de feições nobiliárquicas particulares, e a cultura clássica, objeto de atenção neste artigo, teria um papel também um pouco diferente. Ainda que ultra minoritário, os idiomas latino, grego e, até certo ponto, hebraico, assim como a História e cultura clássica e cristã, passaram a figurar no rol civilizatório da nação. Isso foi recebido e levado adiante pela República, a partir de 1989, com a significativa ampliação do ensino primário e secundário.

Ainda que o tom dominante dessa formação clássica fosse conservador (Haidar, 1972), como não poderia deixar de ser numa sociedade tão desigual e aristocrática, sempre houve lugar para a iluminação crítica. O latinista Fernando de Azevedo (1894-1974) representa muito bem o argumento (Azevedo, 1923), inovador no estudo e na prática de uma educação criativa. No ginásio (fundamental II) e no clássico (médio), o estudo de idiomas clássicos levou até à publicação e vendas copiosas de dicionários MEC, em particular a partir de 1956 (Decreto 38.556, Campanha Nacional de Material de Ensino - CNME). As editoras privadas produziam também livros didáticos de latim e grego, entre outros (Filgueiras, 2013). Esse ápice humanista e democratizante enfrentou um contexto pouco favorável, logo em seguida. Em termos políticos, a Guerra Fria (1947-1989) favorecia a democracia na Europa Ocidental, consolidava ditaduras, autodenominadas do proletariado, a leste, da Alemanha Oriental à China, e contribuíam para a instabilidade na periferia, no então chamado Terceiro Mundo 
(África, América Latina e partes da Ásia). A América Latina conheceu essa instabilidade desde o início (1947), mas isso se acentuou com as guerras ou guerrilhas de descolonização na África e na Ásia, culminando na Revolução Cubana (1959). Isso desencadeou contestações generalizadas, à esquerda e à direita, da democracia liberal. Cuba tornou-se uma ditadura autodenominada do proletariado, diversos movimentos tentaram, por meio de guerrilha, alcançar o mesmo objetivo e, por seu lado, as elites locais e o Ocidente abandonaram a aposta na democracia liberal, em benefício de ditaduras anticomunistas.

No plano econômico, o capitalismo, associado nos Estados Unidos e na Europa à democracia liberal, encontrava-se ligado a ditaduras no Terceiro Mundo, como no caso da América Latina. A tendência geral do capitalismo em direção ao utilitarismo tem levado, repetidas vezes, a adequar o currículo à formação para o mercado de trabalho (Germano, 1994). Isso é algo que só se acentuou com o tempo, como ficou claro com a conversão da China ao capitalismo na década de 1980, seguida pelos restantes países socialistas, com uma ou outra rara exceção. A ditadura militar (1964-1985) iria esposar esse ideário ao propor uma educação tecnicista (Souza, 2009), voltada para uma suposta formação de mão-de-obra para o mercado. Esse é um tema recorrente no mundo todo, tendência acentuada no século XX na busca frenética pela industrialização, tanto no capitalismo, como no socialismo real. A abordagem autoritária, à época, como hoje, em 2019, consiste em não preocupar-se tanto com a real formação técnica, mas com a tentativa de limitação das disciplinas humanísticas, possível fonte de crítica ao poder, lato sensu. Esta restrição liga-se ao medo da $\pi$ $\alpha \varrho \eta \sigma i \alpha$ (parrhesía), pois "dizer a verdade a quem detém o poder" (speak truth to power) implica expor as vísceras do governante, que pode reagir com todo tipo de represália, até a morte. Não à toa, as igrejas que se opunham ao jugo autoritário citavam o caso de João Batista, morto por ser ter sido franco (Mc, 6, 14-29). A formação humanística era abandonada, suprimiam-se os idiomas francês, latim e grego, introduziam-se cursos médios técnicos e profissionalizantes obrigatórios. A ligação com o mundo do trabalho mostrou-se logo uma miragem.

Havia um outro lado, esse mais bem sucedido. As reformas educacionais incluíam a inspiração no sistema de créditos americano, e na criação de uma pós-graduação com mestrado e doutoramento. $\mathrm{O}$ modelo anterior seguia a erudição europeia, em particular francesa, com seu doutoramento muito mais aberto. O novo sistema americano, apoiado pela Capes, gerou um dinamismo insuspeitado e, nas humanidades, fomentou a crescente diversificação e especialização, inclusive nas Humanidades.

\section{OS ANTECEDENTES IMEDIATOS}

Época de contradições e conflitos, como todas. O regime militar endureceu nos seus primeiros quinze anos (1964-1979), com assassinatos, cassações, exílio, atos de exceção, fechamento do congresso, censura, restrições em geral, ainda que sempre mantendo algumas liberdades (eleições para diversos cargos, um partido de oposição, entre outras). Em seguida, seguiu-se um período de abertura, anistia (1979), legalização de partidos, eleições estaduais (1982). Isso culminaria com a escolha de um civil para a presidência (1985) e com a constituição (1988). Esse o contexto geral da criação da SBEC. 
De particular relevância foram dois aspectos: as liberdades, por um lado, e o contato com o mundo, de outro, ambos relacionados. O período mais duro da ditadura, de 1969 a 1979, testemunhou a repressão mais violenta e as políticas de estado mais restritivas e antihumanistas. Paulo Duarte, dentre outros, era aposentado de maneira arbitrária e compulsória. Fechavam-se cursos de Humanas no ensino superior, tentava-se fechar instituições, como o Instituto de Pré-História (Funari, 1994), professores eram perseguidos, inclusive por colegas, que aproveitavam o clima anticomunista para acusar estudiosos que incomodavam ou geravam ciúmes. No ensino fundamental, tentou-se acabar com as disciplinas de História e Geografia, que seriam substituídas, em cópia dos Estados Unidos, por Estudos Sociais. Fechamento do congresso, senadores biônicos e esquadrões da morte conviviam com certa convivência com a sociedade civil, tanto a agrupada pela oposição (MDB, OAB, CNBB), como pelo próprio estado, como a Embrafilme.

A transição estava, pois, em curso, entre repressão e tolerância (Figueiredo e Cheibub, 1982). O regime militar vira com preocupação a Revolução dos Cravos (25/04/1974), comandada por militares e que flertava com o comunismo soviético e chinês. A morte de Franco (1975) e os Pactos de La Moncloa (1977) induziram a autoproclamada Revolução de Março (hoje Ditadura Civil-Militar) a copiar o modelo espanhol de transição negociada: legalização de todos os partidos, sem excluir os comunistas, anistia, retorno dos exilados, fim da censura formal e prévia, restabelecimento das eleições para os governos estaduais (1982), tudo isso levou à convivência dos contrários e favoreceu as liberdades de pensamento e de ação. Isso resultaria na eleição indireta de um civil para a presidência (1984), a posse de um civil (1985), a promulgação de uma nova constituição (1988), o restabelecimento das eleições diretas para presidente (1989).

No ensino fundamental e médio, recuavam as tentativas de sufocar as humanidades e no ensino superior já aumentava a inserção internacional e a variedade de perspectivas e temas. Mesmo no auge da repressão, intelectuais críticos (ou de esquerda, como se preferir), como Michel Foucault, vinham ao Brasil (1973) e Niède Guidon, na contramão da Arqueologia com apoio oficial, desenvolvia projeto humanista, que valorizava a cultura indígena, já com sua Missão Francesa, no mesmo ano de 1973. Neste contexto contraditório, entende-se a criação da SBEC.

\section{A RESISTÊNCIA DEMOCRÁTICA E A ACADEMIA}

A academia, no sentido largo do termo, que inclui universidades, revistas acadêmicas (como a Revista Debate e Crítica), associações científicas, como a Sociedade Brasileira para o Progresso da Ciência e as profissionais (ANPUH, ABA, AGB, entre outras), manteve atuação e fomento do pensamento crítico, durante todo esse período. Os cursos de Problemas Brasileiros, pensados pelo regime como disciplina de adestramento e acomodação, logo foram subvertidos a fim de se refletir, de maneira livre e crítica. Paulo Sérgio Pinheiro, assim, no início da década de 1980, introduzia os seus alunos da USP a autores como Michel Foucault (1977). 
No início da década de 1980 havia, pois, dois aspectos em interação e fermentação na academia: ação e pensamento político crítico e abertura para o mundo. Enquanto cassavamse professores, jovens apenas graduados aproveitavam as oportunidades para exercerem docência universitária e até mesmo para ocuparem posições administrativas. Outros, com titulação no estrangeiro, voltavam ao país também e tomavam posições acadêmicas, tanto em universidades públicas, como, em particular, nas confessionais. Alguns dos cassados retornariam em seguida, tudo isso com resultados notáveis nas Humanidades em geral. Introduziam-se discussões correntes pelo mundo, em particular, preocupações sociais e críticas não só ao poder, como às condições sociais dos subalternos e excluídos. Se isto estava evidente em áreas como Sociologia, Ciência Política e Educação, também acontecia, em medida variável, em História, Filosofia e Letras, áreas que deram início ao que viria a ser a SBEC.

Os primeiros encontros, antes da formalização da SBEC, em 1985, ocorreram nessas circunstâncias, com a realização em Belo Horizonte, em maio de 1984 do I Congresso Nacional de Estudos Clássicos (cf. Zélia Cardoso de Almeida, http:/ /www.classica.org.br/ resources/download/1432849058_ARQUIVO_SBEC20anos-umahistoria.pdf; cf. Ferreira Pinto e Brandão, 1987). A criação da SBEC, no ano seguinte, deu-se na concomitância com reunião da SBPC e contou, na sua direção, com uma presidente com doutorado no estrangeiro (França, Haiganuch Sarian) e com um livre-docente do sistema antigo (Donaldo Schüler), uma mestra (Sílvia Damasceno) e dois graduados (Jacyntho Lins Brandão e Neiva Ferreira Pinto). Ressalte-se a ousadia e novidade da quebra de hierarquias, ao estarem graduados e doutores lado a lado, não só na direção da entidade, como na participação acadêmica. Também deve ser destacada a preponderância feminina da direção da SBEC. Por não fortuita coincidência, criava-se no ano seguinte, também com princípios não hierárquicos e abertos aos jovens estudiosos de diversas áreas, o World Archaeological Congress (1986; Funari, 2006). Havia, pois, como mencionado, um contexto internacional favorável, além do local brasileiro. A participação de estrangeiros, já nesta fase inicial, foi importante para uma preocupação com a erudição, cujo tom foi dado desde o início por Haiganuch Sarian.

Isso não significou repetição colonizada, mas representou a oportunidade de conhecer várias tradições de estudo, nas línguas francesa, inglesa, alemã, italiana e castelhana. Na mesma linha, a experiência brasileira foi fundamental para a renovação dos estudos clássicos no país. Ao lado dos autores e temas canônicos, floresceram outros menos frequentados, ao

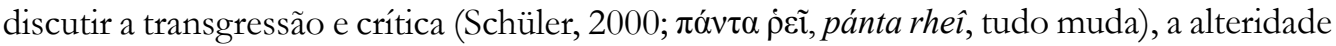
(Brandão, 1990), as camadas populares (Dabdab Trabulsi, 1990), a ironia, os objetos de uso comum e quotidiano, as mulheres, entre outros tantos (cf. Ribeiro, 1985, sobre Nero). A formação brasileira dos classicistas incluía leituras locais fertilizadoras dos clássicos antigos, como podiam ser Padre Vieira (Pécora, 2008), Machado de Assis, Lima Barreto, Caio Prado Jr. (1952), ou Sérgio Buarque de Holanda (1936). Esses autores e as circunstâncias locais serviam para revisitar o mundo antigo com olhos particulares, que geraram interesse no país e no estrangeiro. Em pouco tempo, surgiam títulos de livros publicados no estrangeiro (cf. Sarian, 1989; Dabdab Trabulsi, 1990). 
A revista Classica (1989), na mesma linha, representou passo importante, ao congregar as diversas disciplinas, para além das Letras (História, Arqueologia, Filosofia, Antropologia) voltadas para a Antiguidade. Além disso, a revista publicava, na vanguarda da época, artigos não só de doutores, mas de graduados, mesclados, ainda, a grandes nomes da ciência mundial.

\section{UMA PALAVRA DE BALANÇO E PROSPECTIVA}

Décadas depois, o que se pode dizer? No contexto mundial e brasileiro atual, tão marcado pelo nacionalismo, pelas políticas de identidade, pelos conflitos sociais e ideológicos, a experiência da SBEC e de Classica parece de particular relevância. Alguns dos temas abordados retornam com força, como o embate entre tecnicismo e humanismo/humanidades, comunismo e anticomunismo, nós e eles, localismo e cosmopolitismo, entre outros. O historiador é pouco afeito ao futuro, o arqueólogo um pouco menos, pela profundidade do passado, que pressagia sempre o devir. Mas isso não impede a tentativa de uma consideração do que se passou, e de uma ponderação sobre as possibilidades abertas.

Os Estudos Clássicos no Brasil puderam florescer, em benefício tanto da ação como do pensamento crítico e criativo, em um contexto conflitivo, entre os anos 1970 e 1980. O desenvolvimento da SBEC, de Classica e da ampliação dos estudiosos foi tremendo. Nunca houve tanto interesse, em termos absolutos, em número de pessoas, e relativos, em relação à população e aos acadêmicos. Isso foi importante, nessas décadas, ao contribuir para a formação de uma cidadania mais bem informada e proativa. Mais ainda, nos dias de hoje (Settis, 2006). A investida universal contra a reflexão e o pensamento erudito (ou bem fundamentado, para usar um termo menos carregado) e a ação autônoma das pessoas não devem ser subestimadas. A tecnologia permite o controle, cada vez mais disseminado, do comportamento humano. Isso afeta a todos, da China aos Estados Unidos. O mundo antigo, em sua imensa variedade e diversidade, pode fornecer elementos para a vida libertária e autônoma. A SBEC e Classica fazem parte dessa busca e podem contribuir para isso.

\section{Agradecimentos}

Agradeço a Jacyntho Lins Brandão, José Antônio Dabdab Trabulsi, Neiva Ferreira Pinto, Thomas Patterson, Alcir Pécora, Haiganuch Sarian e Donaldo Schüler. Menciono o apoio institucional da Unicamp, CNPq e Fapesp. A responsabilidade pelas ideias restringe-se ao autor.

\section{REFERÊNCIAS}

AZEVEDO, F. Nos tempos de Petrônio. Ensaios sobre a antiguidade latina. São Paulo: Marrano, 1923.

BORTOLANZA, J. Trajetória do ensino superior brasileiro? Uma busca da origem até a atualidade. In: XVII Colóquio Internacional de Gestión Universitaria, 2017. Mar del Plata, 2017. 
BRANDÃO, J. L. Perspectivas de alteridade na obra de Luciano de Samósata. Classica (São Paulo), São Paulo, v. 3, n. 3, p. 137-48, 1990. DOI: https://doi.org/10.24277/classica.v3i3.602 BUARQUE DE HOLLANDA, S. Raízes do Brasil. São Paulo: Cia. das Letras, 1992 [1936].

CANCLINI, N. G. Hybrid cultures: strategies for entering and leaving modernity. Minneapolis: University of Minnesota Press, 1995.

CUNHA, L. A. A Universidade temporã, o ensino superior, da Colônia à Era Vargas. 3.ed. São Paulo: Editora da Unesp, 2007.

DABDAB TRABULSI, J. A. Dionysisme, pouvoir et société. Bensançon: Les Belles Lettres/Alub, 1990.

FERREIRA PINTO, N.; BRANDÃO, J. L. (Org.). Cultura clássica em debate. v. 1. Belo Horizonte: UFMG/CNPq/SBEC, 1987.

FIGUEIREDO, M. F; CHEIBUB, J. A. B. A abertura política de 1973 a 1981: quem disse o quê e quando - inventário de um debate. BIB - Boletim Informativo e Bibliográfico de Ciências Sociais, 14, p. 29-61, 1982.

FILGUEIRAS, J. M. A produção de materiais didáticos pelo MEC: da Campanha Nacional de Material de Ensino à Fundação Nacional de Material Escolar. Revista Brasileira de História, São Paulo, v. 33, n. 65, p. 313-35, 2013.

FOUCAULT, M. Vigiar e punir. Petrópolis: Vozes, 1977.

FUNARI, P. P. A. The world archaeological congress from a critical and personal perspective. Archaeologies, Blue Ridge Summit, USA, v. 2, n. 1, p. 73-9, 2006.

FUNARI, P. P. A. Paulo Duarte: pela dignidade universitária. Idéias, v. 1, n. 1, p. 155-179, 1994.

GERMANO, J. W. Estado militar e educação no Brasil (1964-1985). 2 ed. São Paulo: Cortez, 1994.

HAIDAR, M. L. M. O ensino secundário no império brasileiro. São Paulo: Edusp, 1972.

KUHN, T. A estrutura das revoluções científicas. Trad. B. V. Boeira e N. Boeira. São Paulo: Perspectiva, 1996.

LATOUR, B. Nousn'avons jamais été modernes: essai d'anthropologie symétrique. Paris: La Découverte, 1991.

ORTIZ, F. Del fenómeno social de la «transculturación» y de su importancia en Cuba. Tomado de Contrapunteo cubano del tabaco y el azúcar. Editorial de Ciencias Sociales, La Habana, 4, p. 86-90, 1983. Revisado el 17 de Octubre de 2011: http://www.ffo.cult.cu/downloads/ortiz/ Del_fenomeno_social_de_la_transculturacion.pdf.

PATTERSON, T. A social history of anthropology in the United States. Oxford \& New York: Berg, 2001. 
PÉCORA, A. Teatro Sacramento-A unidade teológico-retórico-politica dos sermões de Antonio Vieira. Campinas/SP: Editora da Unicamp, 2008.

PRADO JR., C. Dialética do Conhecimento. São Paulo: Brasiliense, 1952.

RIBEIRO, D. V. Nero e o incêndio de Roma. Revista do Departamento de História, Fafich/UFMG, Belo Horizonte, v. 1, p. 62-75, 1985.

SARIAN, H. La civilisation mycénienne: continuités et ruptures. In: TREUIL, R.; DARCQUE, P.; PORSAT, J.-C.; TOUCHAIS, G. (Org.). Les Civilisations Égéennes: le Néolitbique et l'Âge $d u$ Bronze de l'Anatolie aux Balkans. Paris: Presses Universitaires de France, 1989, v. 1, p. 585-93.

SCHÜLER, D. Heráclito e seu (dis)curso. 1. ed. v. 1. Porto Alegre: L\&PM, 2000.

SCHÜLER, D. Teoria do romance. 1. ed. São Paulo: Ática, 1989.

SETTIS, S. The future of the 'classical'. Cambridge: Polity Press, 2006.

SOUZA, R. F. de. A renovação do currículo do ensino secundário no Brasil: as últimas batalhas pelo humanismo (1920-1960). Curriculo sem Fronteiras, 9/1, p. 72-90, 2009. 